\title{
The Gold Mine of Nationally-funded Projects
}

\author{
B. Giovani ${ }^{1 \text {,* }}$, G. Anthoine ${ }^{2}$, S. Blümel ${ }^{3}$, M. L. Cruz ${ }^{4}$, A. de la Peña ${ }^{5}$, E. Steel ${ }^{6}$, M. Maes ${ }^{7}$, M. Schenk ${ }^{8}$, \\ J.G. Unger'
}

\author{
${ }^{1}$ European and Mediterranean Plant Protection Organization, (EPPO) Paris, France \\ ${ }^{2}$ French Agency for Food, Environmental and Occupational Health and Safety (ANSES), France \\ ${ }^{3}$ Austrian Agency for Health and Food Safety (AGES), Austria \\ ${ }^{4}$ National Institute for Agriculture and Veterinary Research (INIAV), Portugal \\ ${ }^{5}$ National Institute for Agricultural Research and Food Technology (INIA), Spain \\ ${ }^{6}$ Department for Environment Food \& Rural Affairs (DEFRA) London, United Kingdom \\ ${ }^{7}$ Institute for Agricultural and Fisheries Research (ILVO), Belgium \\ ${ }^{8}$ National Plant Protection Organisation (NPPO), The Netherlands \\ ${ }^{9}$ Julius Kuhn Institute (JKI), Germany
}

Copyright $(2016$ by authors, all rights reserved. Authors agree that this article remains permanently open access under the terms of the Creative Commons Attribution License 4.0 International License

\begin{abstract}
The Euphresco (European phytosanitary research coordination) network is an ERA-NET initially funded by the $6^{\text {th }}$ and $7^{\text {th }}$ EU Framework Programmes as an initiative to enhance public-public partnership in the statutory plant health sector. An inventory was organised in 2015 to collect information on the national phytosanitary research programmes and their research projects in the EPPO region. The information collected through the Euphresco inventory provides precious insights into national research activities to avoid programme duplication and to increase programme depth among the phytosanitary research funders of the EPPO region and beyond.
\end{abstract}

Keywords Euphresco, ERA-NET, Plant Health Research Coordination, Inventory (Mapping), National Research Programmes

\section{Introduction}

European integration and the development of the European Union pass through the implementation of a number of EU, national and grassroots initiatives. At the Lisbon European Council in March 2000 the concept of a European Research Area (ERA) was developed as a response to the challenges of globalisation. ERA is a single space for research and innovation, where knowledge, ideas, technologies and researchers can move freely and where research activities at the national and EU level are well integrated and coordinated [1]. Despite these ambitions, 85\% of public research and development (R\&D) in the EU is still programmed, financed, monitored and evaluated at national level, with little collaboration or coordination between countries [2]. This national approach to research policy results in fragmentation and inevitable duplications of research efforts, gaps and non-efficient (industrial) exploitation of research outputs. The Euphresco (European phytosanitary research coordination) network is an ERA-NET initially funded $(2006)$ by the $6^{\text {th }}$ and $7^{\text {th }}$ EU Framework Programmes as an initiative to enhance public-public partnership in the European statutory plant health sector and to address the 'state of emergency' of the phytosanitary area, facing an erosion of the scientific basic knowledge (taxonomy, classical plant pathology, etc.) and constraints of funding and personnel that could prevent the National Plant Protection Organisations to do their duty [3]. In April 2014 Euphresco http://www.euphresco.net/ became an international long-term sustainable network with the same goal of better use of limited public R\&D funds through enhanced cooperation.

\section{Methodology}

Knowledge exchange is at the foundation of collaboration; besides fostering and encouraging a spirit of trust and openness, it contributes to the dissemination of best practices and empowers those participating to the 'exercise'. In order to shed light on national research programmes and projects, in spring 2015 Euphresco members agreed to launch an inventory in the EPPO member countries. The goal of the inventory was to collect information on on-going national phytosanitary (quarantine/statutory plant health) research programmes and their research projects in the EPPO region, which counted 50 members in 2015. 110 research programme owners (typically national ministries/regional authorities responsible for defining, financing or managing programmes carried out at national or regional level) and programme managers (research councils, funding agencies 
or other entities that implement national or regional research and innovation programmes under the supervision of the programme owners) were identified in twenty six countries. Three countries stated that they did not have specific phytosanitary research infrastructures and twenty one member countries did not provide any answer (figure 1).

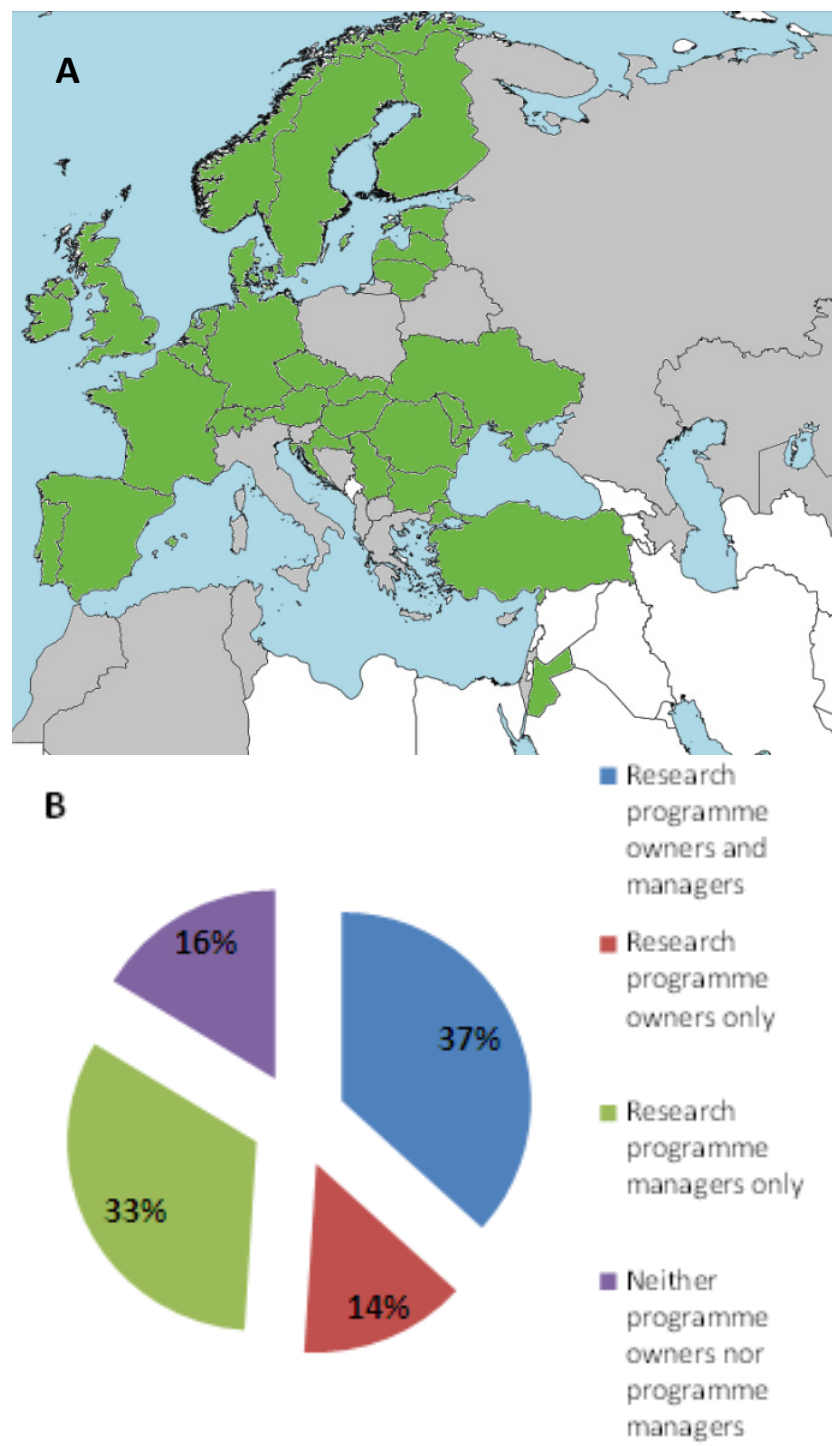

Figure 1. Phytosanitary research programme owners and managers in the EPPO region. A) Respondents to the survey: in green are highlighted EPPO members from which answers were received from at least one organisation established in the country; in grey are highlighted EPPO members that did not participate in the inventory; B) Categories of respondents.

\section{Results}

\subsection{Phytosanitary Research Programmes}

The inventory highlighted 55 phytosanitary research programmes (figure 2), defined as 'coordinated sets of projects undertaking related research often at national or even international level, with government funding' active in 2015.

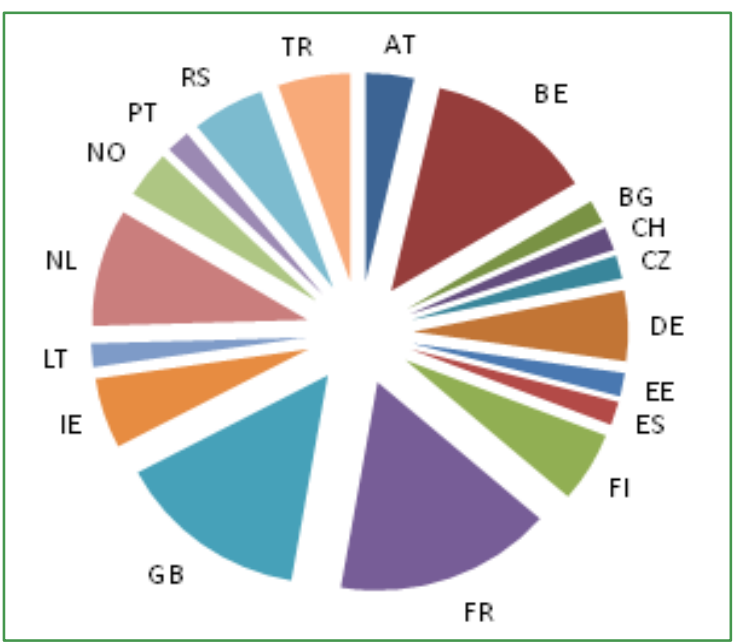

Figure 2. Phytosanitary research programmes in the EPPO region declared in the 2015 Euphresco mapping. AT: 2 programmes; BE: 7 programmes; $\mathrm{BG}$ : 1 programme; $\mathrm{CH}: 1$ programme; CZ: 1 programme; DE: 3 programmes; EE: 1 programme; ES: 1 programme; FI: 3 programmes; FR: 9 programmes; GB: 8 programmes; IE: 3 programmes; LT: 1 programme; NL: 5 programmes; NO: 2 programmes; PT: 1 programme; RS: 3 programmes; TK: 3 programmes.

The programmes identified were discrete phytosanitary research programmes, i.e. focusing exclusively or mainly on plant health, or were part of larger agronomical/environment research programmes. It was not possible to define an exact budget for all research programmes, as a number of them are continuous programmes (not funded or defined for a given period of time) or because the information was not provided. Nevertheless it was possible to define the funds allocated to phytosanitary research projects based on their start date, end date and duration. The value of phytosanitary research projects funded by the respondents is shown in figure 3 . Three years (2013, 2014 and 2015) are shown, while information on previous years was omitted; because the inventory only focused on phytosanitary research programmes that were active at the date the survey was sent and because the start and end date of each national programme differ, we assessed that only data from very recent years would provide a trustworthy picture of the financial resources allocated by the respondents. Still, the diagram in figure 3 does not take into account confidential budgets or information that was not provided by the funders or partially provided. Also relevant to mention, a number of countries, members of the Euphresco network, funded phytosanitary research of transnational consortia and the budget committed through Euphresco in 2015 is presented separately (figure 4). Thus, the indicated figures should be considered an underestimation of the total budget allocated in 2013, 2014 and 2015 by the organisations which provided information. The mapping covering more countries than those that were members of the Euphresco network and the participation of organization in Euphresco projects being decided nationally, the countries listed in figure 3 and 4 are not the same. 


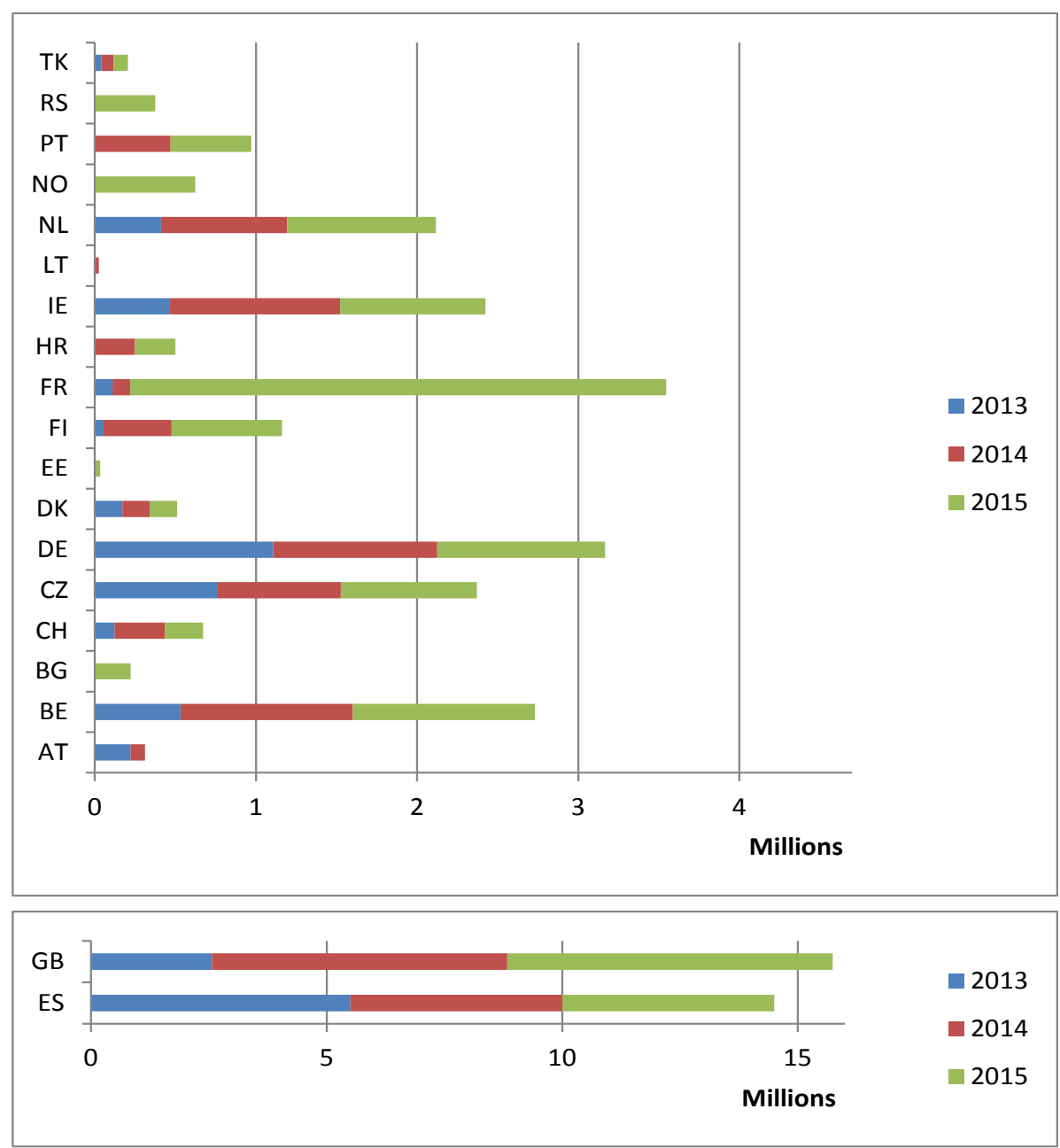

Figure 3. Budget allocated to national phytosanitary research projects for the years 2013,2014 and 2015 . The total budget amounted $12.1 \mathrm{M} €$ ca in 2013 , 17.4 M€ ca in 2014 while funds allocated until summer 2015 accounted for $22.8 \mathrm{M}$ ca. The diagram does not take into account confidential budgets, figures that were not provided by the funders, or the budget allocated through Euphresco (see figure 4).

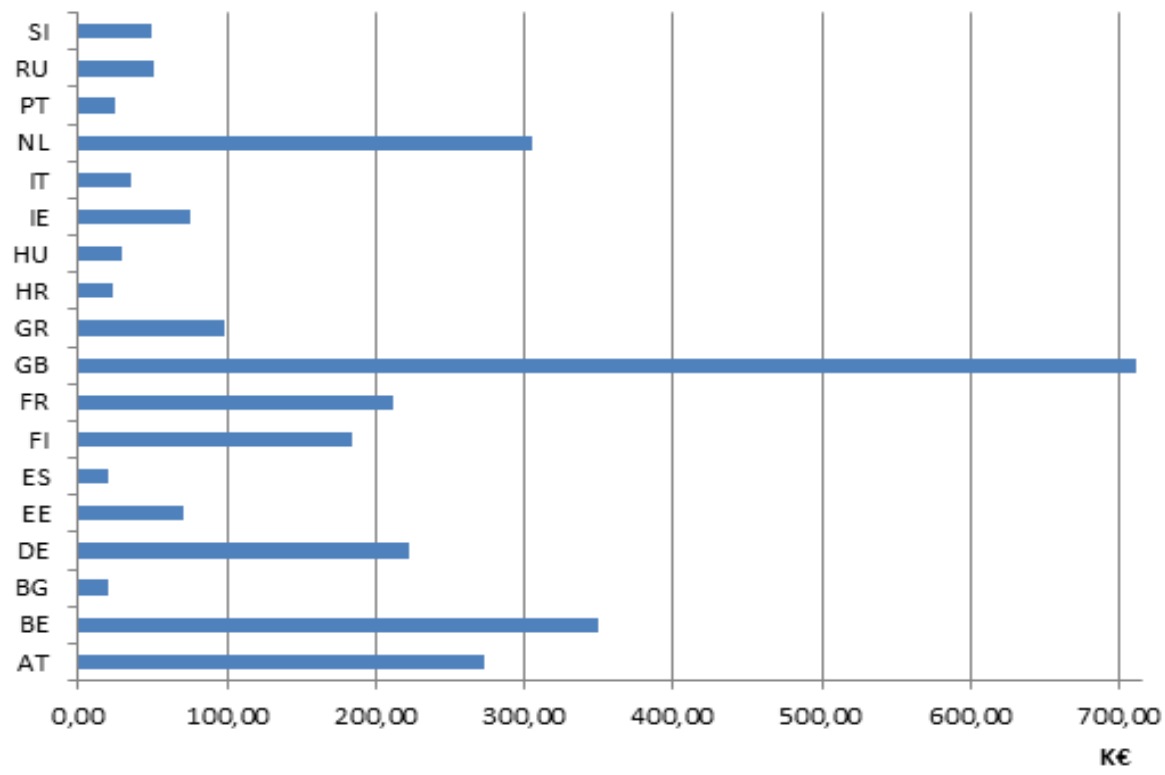

Figure 4. Budget (per Euphresco member country http://www.euphresco.net/about/members) committed to transnational phytosanitary research projects funded through Euphresco in 2015. The total budget committed by Euphresco member organisations in the EPPO region was $2.8 \mathrm{M} €$. 


\subsection{National Phytosanitary Projects}

Information on more than 250 research projects was gathered. These projects covered a wide budget range, with a minimum of 3000 Euros up to a maximum of $9.5 \mathrm{M} €$. Half of the projects were small, having a budget below $100 \mathrm{~K} €$. Only a few projects (22) were supported with more than 1 $\mathrm{M} €$. This is not surprising as phytosanitary research efforts in the EPPO region are oriented towards applied research, defined as investigation directed primarily towards a specific practical aim' [4] and the granted funds take into account that projects are very targeted and focus generally on a specific pest or pathogen. The fact that more exploratory research, multidisciplinary or horizontal approaches demanding larger budgets are only marginally funded can be put down to a number of factors: the outputs are not immediately exploitable by the funders, the reduction of resources allocated to phytosanitary research, the limited research capacity within one country and that other research funders (e.g. the European Commission) tend to fund fundamental research.

The projects were classified based on scientific criteria such as the pests/pathogens they focused on, the research activities and the project's outputs and also administrative criteria like the type of funding mechanisms and the project's budget. The research focus was homogeneously distributed among the different types of pests and organisms (figure 5) with the exception of invasive alien plants that attracted only $2 \%$ of the total research effort mapped. This is in agreement with the previous Euphresco inventory (2007) [5]

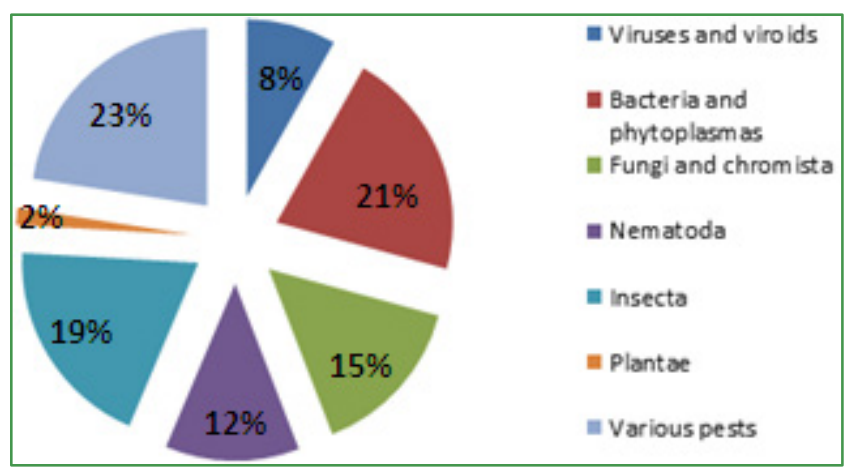

Figure 5. Distribution of research projects over different categories of pests and pathogens of interest in the EPPO region. Viruses and viroids accounted for $8 \%$, bacteria and phytoplasmas were the focus of $21 \%$ of the research projects in the inventory, fungi and chromista weighed $15 \%$ of the total, nematodes were $12 \%$, insects $19 \%$, plants $2 \%$ and $23 \%$ of the projects focused on more than one type of pest (insects and fungi, bacteria, viruses and viroids, insects and nematodes, etc.)

that showed similar percentages. We observed a $50 \%$ reduction of research projects focusing on viruses and viroids; this reduction cannot only be attributed to the incompleteness of our inventory. In the early 2000's a number of viruses affecting tomatoes (Solanum lycopersicum) were detected in Europe, which could explain the increased research efforts to improve diagnostic capacity but also to understand pathogens' biology and the risks associated with them. Pepino mosaic virus (PepMV) is one of these viruses; originally described in Peru, it raised attention when it was found on greenhouse tomatoes in the Netherlands, Spain and the United Kingdom, and in other (protected) tomatoes production areas worldwide.

The top research priorities (figure 6) for bacteria and phytoplasmas were Xylella fastidiosa, 'Candidatus Liberibacter solanacearum' and Phytoplasma pyri (and other phytoplasmas). $X$. fastidiosa is one of the most dangerous bacteria for plant health and is responsible for a large number of diseases in many hosts of high economic value. Since 2012, different European countries have reported interceptions of contaminated coffee plants from South America, [6,7] and the bacterium has also been detected in olive trees and several ornamental plants. The recent outbreaks of X. fastidiosa in Italy and France [7] constitute a major change to its geographical distribution. Important research efforts have been implemented both nationally and regionally and we expect that research commitment on $X$. fastidiosa will continue over the next few years.

Among fungi and chromista (and considering all pests and pathogens inventoried by Euphresco), Hymenoscyphus fraxineus is by far the most studied pathogen. The fungus is not regulated, and the funded projects mainly answered specific national needs; this 'new' disease, Ash Dieback has recently become an emergent problem in (northern) Europe; its potential impact on ash trees (Fraxinus excelsior), a common species in woodlands, hedgerows, parks and gardens, is likely to be significant. This disease attracted an unprecedented level of media and political attention in the UK resulting in the initiation of six research projects working on the biology, the spread, control, resistance and the development of citizen science approaches to identify infected trees. A further four projects on Ash Dieback were funded in Sweden, a country where trees and forest are both culturally and economically important.

A number of insects threatening agriculture and the natural environment in the EPPO region have been introduced in recent years, among them Anoplophora glabripennis (first report in Austria in 2001), Tuta absoluta (first report in Spain in 2008), Drosophila suzukii (first report in Italy in 2010) and Dryocosmus kuriphilus (first report in Italy in 2003). The NPPO of Germany reported [8] a number of findings in its territory (Baden-Württemberg, Bavaria, North Rhine-Westphalia and Saxony-Anhalt) and a number of research projects have been funded since to support pest-risk analysis and analysis of the development of an outbreak and its economic impact. The national research efforts on Tuta absoluta and Drosophila suzukii have focused on the management of the pests (use of predators, pesticides efficiency, etc.). The high reproduction rates of the two species and capacity for natural spread would probably make their containment or eradication difficult; resistance to insecticides has also been observed in South America for Tuta absoluta, which justifies the scope of the funded projects. Three research projects (two funded in Belgium and another in the Netherlands) focused on Monochamus spp. as vectors of Bursaphelenchus xylophilus, the pinewood nematode. 
Research projects on nematodes focused on genera that have been known for a long time as a problem for potato cultivation and trade: Globodera spp., Meloidogyne spp. For Globodera spp., the research projects covered both its detection and management/control. We speculate that the interest about Globodera spp. can be attributed to the importance of their main host potato (Solanum tuberosum), the availability of cultivars that have only partial resistance to $G$. pallida, which is progressively replacing $G$. rostochiensis (for example in the United Kingdom) and the ban of effective soil fumigants (e.g. methyl bromide) in the EU which will have an impact on nematodes that have survival strategies in the soil. Research projects on Meloidogyne spp. have been funded in Turkey and the Netherlands, probably as a result of the recent reports of Meloidogyne chitwoodi and Meloidogyne fallax [9,10].
Protection of plant health is based on three activities: 1) predicting and prioritising risks; 2) preventing introduction of pests and pathogens; 3) containing problems and protecting agriculture and environment. These needs are reflected in the research activities undertaken in the national projects inventoried (figure 7, see columns highlighted in red, orange and green): risk analysis to identify pathways and pests, diagnostics for the development and validation of tests for the detection/ identification of pests and pathogens and management to develop, improve, adapt and test (chemical, physical and biological) measures for the control and eradication of pests, pathogens and their vectors. The other research activities, i.e. characterisation of pests and vectors, epidemiology, economics, mapping, modelling, surveillance and taxonomy produce knowledge and information to feed the main abovementioned activities.

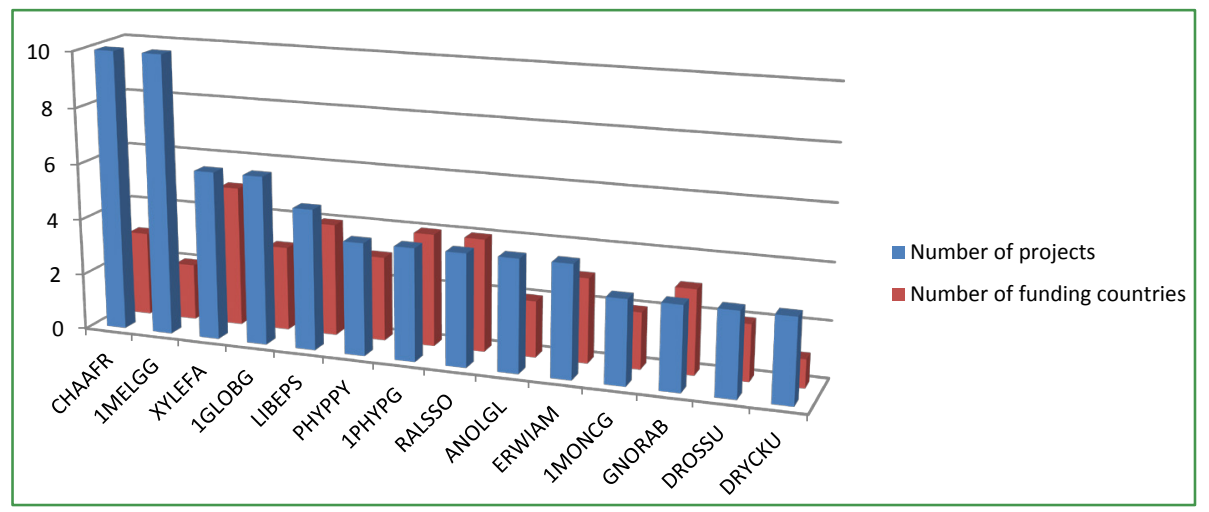

Figure 6. Top pests and pathogens in national projects funded from 2013 to 2015. Both the number of research projects (blue columns) and the number of funding countries (red columns) are indicated. CHAAFR: Hymenoscyphus fraxineus; 1MELGG: Meloidogyne; XYLEFA: Xylella fastidiosa; 1GLOBG: Globodera; LIBEPS: Liberibacter solanacearum; PHYPPY: Phytoplasma pyri; 1PHYPG: phytoplasmas; RALSSO: Ralstonia solanacearum; ANOLGL: Anoplophora glabripennis; ERWIAM: Erwinia amylovora; 1MONCG: Monochamus; GNORAB: Tuta absoluta; DROSSU: Drosophila suzukii; DRYCKU: Dryocosmus kuriphilus.

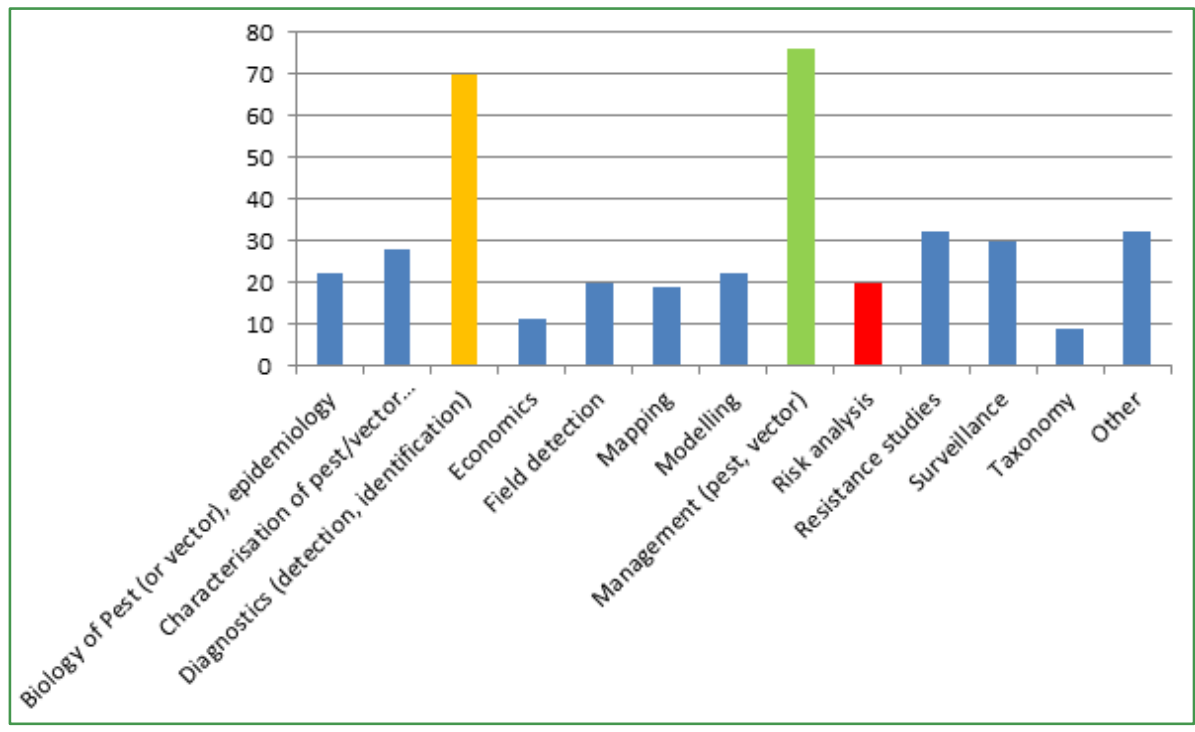

Figure 7. Research activities in the nationally-funded research projects. 


\section{Discussion}

Even if fragmented, the information collected through the Euphresco inventory will provide, in the next months, precious insights into national research activities to avoid programme duplication and to increase programme depth among the phytosanitary research funders of the EPPO region and beyond. At first glance, a trend can be observed: most of the research efforts are funded and implemented as an answer to the threat represented by pests or pathogens that have already entered in a country. This provides the opportunity to fine tune research efforts, to target a concrete problem and to optimise the use of limited resources compared to an approach addressing the unknowns. Is this the correct approach? Should plant health funders adopt a more strategic approach and put more efforts to identify risks before they become a problem? This will need better tools and increased knowledge (e.g. on pathways) to support pest risk analyses and a global approach to plant health. The Euphresco network could have a role to play.

Euphresco members are currently working on a strategic research agenda, a supranational document providing recommendations on the strategic medium-term (five to ten years) research objectives for the plant health sector in the EPPO region. The document will be developed along the new EU plant health legislation and will also take into account the gaps and opportunities identified in the mapping. As Euphresco members will play a major role in the implementation of the agenda's recommendations, synergies with regional funders (i.e. the European Commission and the European Food Safety Authority) should be identified to develop a bottom-up approach combined with strategic European-level guidance [2].

Where there are research activities there are knowledge and expertise and the Euphresco mapping will facilitate pooling of experts that are scattered across different countries. A huge amount of data is produced annually by nationally-funded research consortia but this information is at the moment hidden within countries and cannot benefit to the plant health community at large. Is there a way to make it available so it can be used and re-used in order to develop capacity on which to build future activities?

\section{Conclusions}

The information collected with the inventory is now in the hands of those organisations that have participated in the survey. It is the ambition of the Euphresco members to develop an online searchable database that will allow to collect data on future phytosanitary research projects and to retrieve information on past research projects and programmes, in order to efficiently exploit the gold mine of nationally-funded research.

\section{Acknowledgements}

We thank Françoise Petter, Anne-Sophie Roy and Camille Picard for many stimulating discussions.

\section{REFERENCES}

[1] Frenken K., Koekman J., van Oort F. Towards a European research Area. NAi Publishers, Rotterdam, 2007

[2] European Commission. Toward joint programming in research: working together to tackle common challenges more effectively, 2008. Online available from: http://eur-lex.europa.eu/legal-content/EN/TXT/?uri=celex:52 $008 \mathrm{DC} 0468$

[3] EPPO. Plant Health Endangered - State of Emergency, 2004. Online available from: https:/www.eppo.int/STANDARDS/ position_papers/madeira.htm

[4] Frascati manual: proposed standard practice for surveys on research and experimental development, $6^{\text {th }}$ edition OECD, 2002

[5] Euphresco Deliverable 2.2. Report on the mapping and analysis of national phytosanitary (quarantine/regulated plant health) research programmes (2007). Online available from http://www.euphresco.net/media/deliverables/eu_i/d2.2.pdf

[6] EPPO. Reporting Service 2012/165, 2012. Online available from https://gd.eppo.int/reporting/article-2371

[7] EPPO. Reporting Service 2015/181, 2015. Online available from https://gd.eppo.int/reporting/article-5128

[8] EPPO. Reporting Service 2014/184, 2014. Online available from https://gd.eppo.int/reporting/article-3277

[9] EPPO. Reporting Service 2009/063, 2009. Online available from https://gd.eppo.int/reporting/article-148

[10] EPPO. Reporting Service 2011/109, 2011. Online available from https://gd.eppo.int/reporting/article-250 